\title{
Modelling episode of Saharan dust transfer over the Black Sea according to the WRF model and MODIS satellite data
}

\author{
Anna Papkova ${ }^{1, *}$, Yulia Papkova ${ }^{2}$, and Dmitrii Shukalo ${ }^{1}$ \\ ${ }^{1}$ Marine Hydrophysical Institute of RAS, Sevastopol, 299011, Russia \\ ${ }^{2}$ Sevastopol State University, Sevastopol, 299053, Russia
}

\begin{abstract}
A high dust load from the Sahara Desert is recorded annually over the Black Sea region. To make a reliable forecast for the level of dust, many external factors such as the wind energy, the soil content in the moisture are to be considered. The physical characteristics of the aerosol particles in the atmosphere are also very important. This study focuses on the prediction of dust content for the Black Sea region by using the WRFdust model. Prolonged dust transport over the Black Sea was recorded during the period from September 25 to September 30, 2020. On these days, MODIS satellite images, return trajectories of AERONET and optical parameters of the atmosphere were analyzed.
\end{abstract}

\section{Introduction}

A high dust load from the Sahara Desert is recorded annually over the Black Sea region [1]. It is the dust aerosol that determines the variability of the incident solar radiation and radiation reflected from the Earth. These interactions are regulated not only by the spacetime distribution, but also by its microphysical, optical, and chemical properties [2].

In this research, WRF-Chem tools are used as the basic components in the forecasting model. WRF-Chem is essentially the Weather Research and Forecasting (WRF) model strongly coupled with Chemistry. The model focuses on simulation of trace gases emissions, transport, mixing, and chemical transformation and aerosols simultaneously with the meteorology. This model can be effectively used to investigate regional-scale air quality, field program analysis, and cloud-scale interactions between clouds and chemistry [3]. It can also be used as a supplement when identifying the place of origin of dust aerosol, which is indeed, very useful in studying the physicochemical properties of aerosol [4]. This paper examines the consistency of the results of predicting the dust of the WRF model with the MODIS satellite, CALIPSO and AERONET data according to dust transport over the Black Sea which was recorded during the period from September 25 to September 30, 2020.

Earlier, a similar study was conducted for the WRF-Chem model simulations of a dust outbreak over the central Mediterranean, in which the authors used MODIS-Terra remote sensing data and sun photometers AERONET. Their study showed that the model was able

\footnotetext{
* Corresponding author: hanna.papkova@gmail.com
} 
to reproduce quite well the horizontal field of the aerosol optical depth (AOD) and its evolution in time (temporal correlation coefficient with AERONET of 0.85) [5]. The first step in this study is the modeling of the trajectory of movement of aerosol clouds (particles) from the Sahara started from 25 September 2020 and study information for given dates from other ground sources and remote sensing data.

The aerosol optical thickness (AOT) parameter was also used as the main optical characteristic of the state of the atmosphere, as it indicates the aerosol turbidity of the atmosphere and the ecological state of the air basin. In addition to the analysis of aerosol back trajectories the corresponding values of the AOT parameter will be recorded on the days of dust transport predicted by the WRF model. This solution enables to evaluate predictions results with higher accuracy. AOT parameter data will be retrieved from the MODIS satellite data.

Sand and dust storms have many negative impacts on the agricultural sector including: reducing crop yields by burial of seedlings under sand deposits, the loss of plant tissue and reduced photosynthetic activity as a result of sandblasting, delaying plant development, increasing end-of-season drought risk, causing injury and reduced productivity of livestock, increasing soil erosion and accelerating the process of land degradation and desertification, filling up irrigation canals with sediments, covering transportation routes, affecting water quality of rivers and streams, and affecting air quality.

The relevance of the study is fully justified by the fact that the overestimated concentrations of absorbing aerosol particles generated from organic aerosol and anthropogenic pollutants will surely have a negative impact on human health with subsequent exacerbation of chronic cardiopulmonary diseases [6].

\section{Methods and research area}

In the current research, a set of dates with predicted dust pollution of the atmosphere and corresponding reverse trajectories of the aerosol was collected using data from WRF-Chem model and AERONET site. The main source of remote sensing data the MODIS satellite was used. Later, some supplements have been found with the help of CALIPSO model.

\subsection{WRF-Chem model}

WRF-Chem version 4 is used in this study. The Weather Research and Forecasting (WRF) model is a mesocale numerical weather prediction system designed to serve both operational forecasting and atmospheric research needs. The detailed description of WRF model can be found in Ref [7]. In addition to the dynamic calculation model of dust linked with the WRF model, and the resulting model is now defined as WRF-Dust model. The physical parameters of dust aerosol in WRF-Dust model are the same as those of the dust modules developed by the GOCART model (Georgia Tech/Goddard Global Ozone Chemistry Aerosol Radiation and Transport model). WRF-Dust is a non- hydrostatic model running once daily at the National Observatory of Athens (1200 UTC cycle). One domain is used covering a large part of Sahara (main source of mineral dust), the Mediterranean and Black seas, Europe, with $20 \mathrm{~km}$ horizontal grid increment. In the WRF-Chem model there are 5 dust size bins. The dust particles have mean radius of bins $0.6,1.2,2.4,4.5$, and 8.0 $\mu \mathrm{m}$, respectively. The dust emission in each dust particles size bins is size-resolved, which is calculated by taking into account the soil particle fraction, erosion factor, surface wind velocity, and the threshold velocity of wind erosion. 


\subsection{AERONET network}

In present research, we have used 7-day back trajectories of aerosol transfer are based on kinematic trajectory analysis using assimilated gridded analysis data from NASA GMAO (Global Modeling Assimilation Office) and NCEP (National Centers for Environmental Prediction) analysis. Currently 7-back trajectory analyses are generated twice a day (00Z and 12Z) and two sets of images are generated: The first set has trajectory analyses starting at four pressures levels ( $950 \mathrm{hPa}, 850 \mathrm{hPa}, 700 \mathrm{hPa}$ and $500 \mathrm{hPa}$ ) at each of the AERONET sites - these levels correspond to altitudes of approximately .5, 1.5, 3, and 5 kilometers, respectively. In addition, the second set of images contains the above 4 levels as well as 4 higher levels (400, 300, 250, and $200 \mathrm{hPa}$ ) - corresponding to approx. altitudes of 7, 9, 10, and 12 kilometers [8].Nowadays, AERONET network in the Black Sea region is represented by 3 regularly measuring stations: Galata_Platform (43,045N, 28,193E), Eforie $(44,075 \mathrm{~N}, 28,632 \mathrm{E})$ and Section-7_Platform $(44.546 \mathrm{~N}, 29.447 \mathrm{E})$. It is worth noting that at the moment the backward trajectories are still calculated for stations that have stop functioning, for example: Sevastopol (44.616N, 33.517E) and Gloria (44.600N, 29.360E).

\subsection{MODIS Terra/Aqua}

MODIS (or Moderate Resolution Imaging Spectroradiometer) is a key instrument aboard the Terra (originally known as EOS AM-1) and Aqua (originally known as EOS PM-1) satellites. Terra MODIS and Aqua MODIS are viewing the entire Earth's surface every 1 to 2 days, acquiring data in 36 spectral bands, or groups of wavelengths (see MODIS Technical Specifications). These data will improve our understanding of global dynamics and processes occurring on the land, in the oceans, and in the lower atmosphere. MODIS data provide a number of important optical characteristics of the atmosphere such as: aerosol optical depth, remote sensing reflectance, aerosol particle radius, water vapor, etc.

\section{Results}

Dust bursts were tracked by the author from 25 September 2020 to 30 September to carry out the investigation. Forecasting took place 2-3 days from a fixed date. Tracking was performed using WRF-dust based dust load maps showing hourly concentration and movement of the dust cloud (Fig. 1).

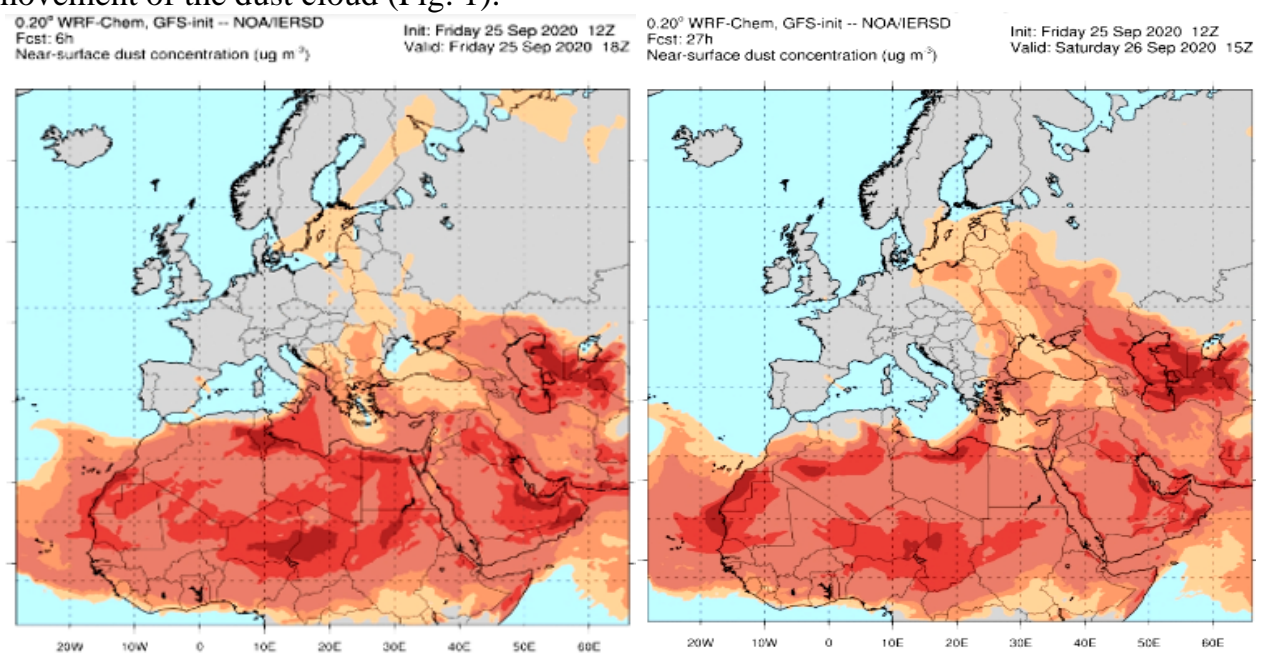



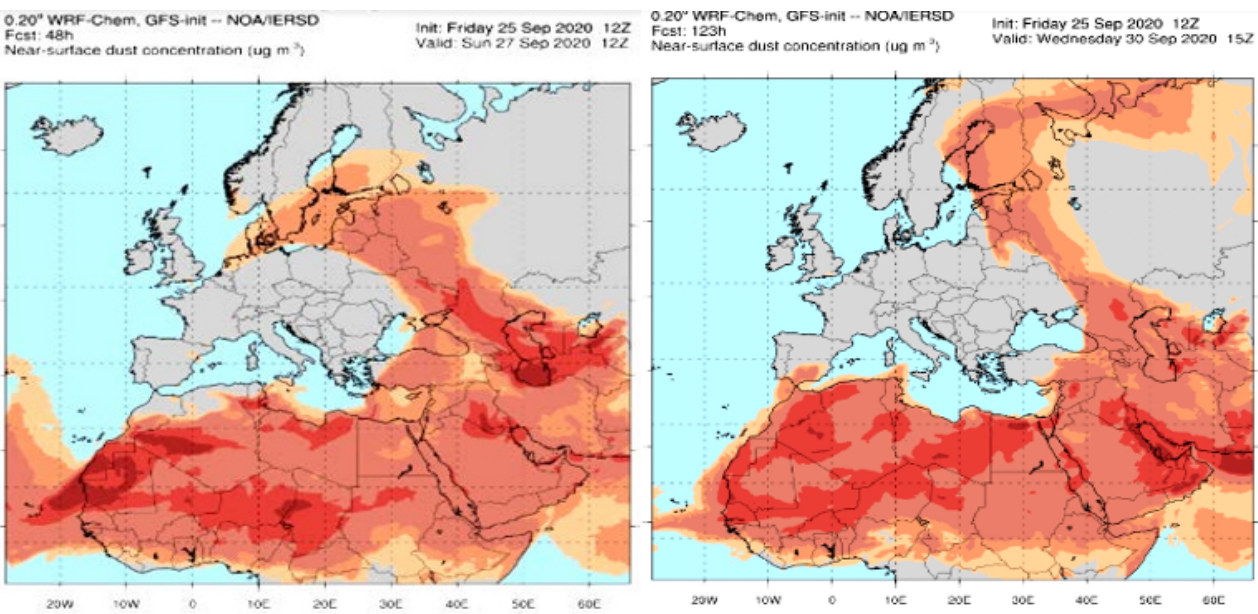

Fig. 1. Maps for predicting the presence of dust aerosol using the WRF-dust model from 25.09.2020 to 30.09 .2020 .

For each of the dates, the reverse trajectories of the origin of atmospheric aerosol were tracked for the three Black Sea stations of the AERONET network (Gloria, Eforie, Sevastopol). The return trajectories for the two stations Eforie and Gloria confirmed the dust transfer. Moreover, based on the starting points of the trajectories, the aerosol originated directly from the Sahara desert (Fig.2).

Thus, the return trajectories of AERONET and MODIS satellite images confirmed the presence of Sahara dust transfers towards the Black Sea (Fig. 3).

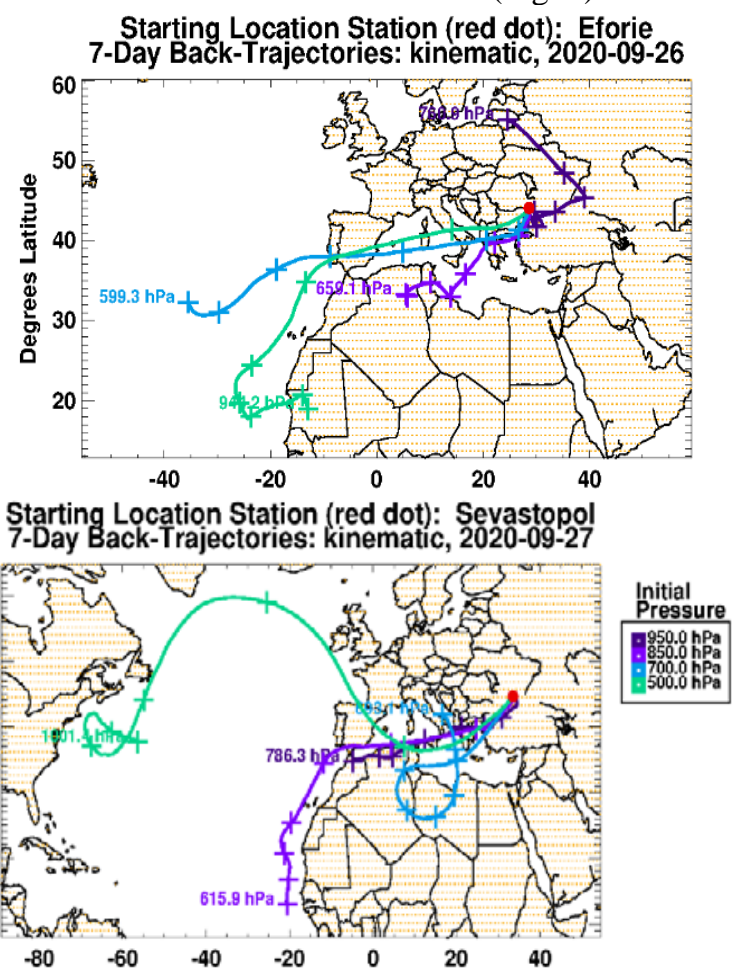

Fig. 2. Backward trajectories of AERONET on the days of dust transport predicted by the WRF-Dust model. 


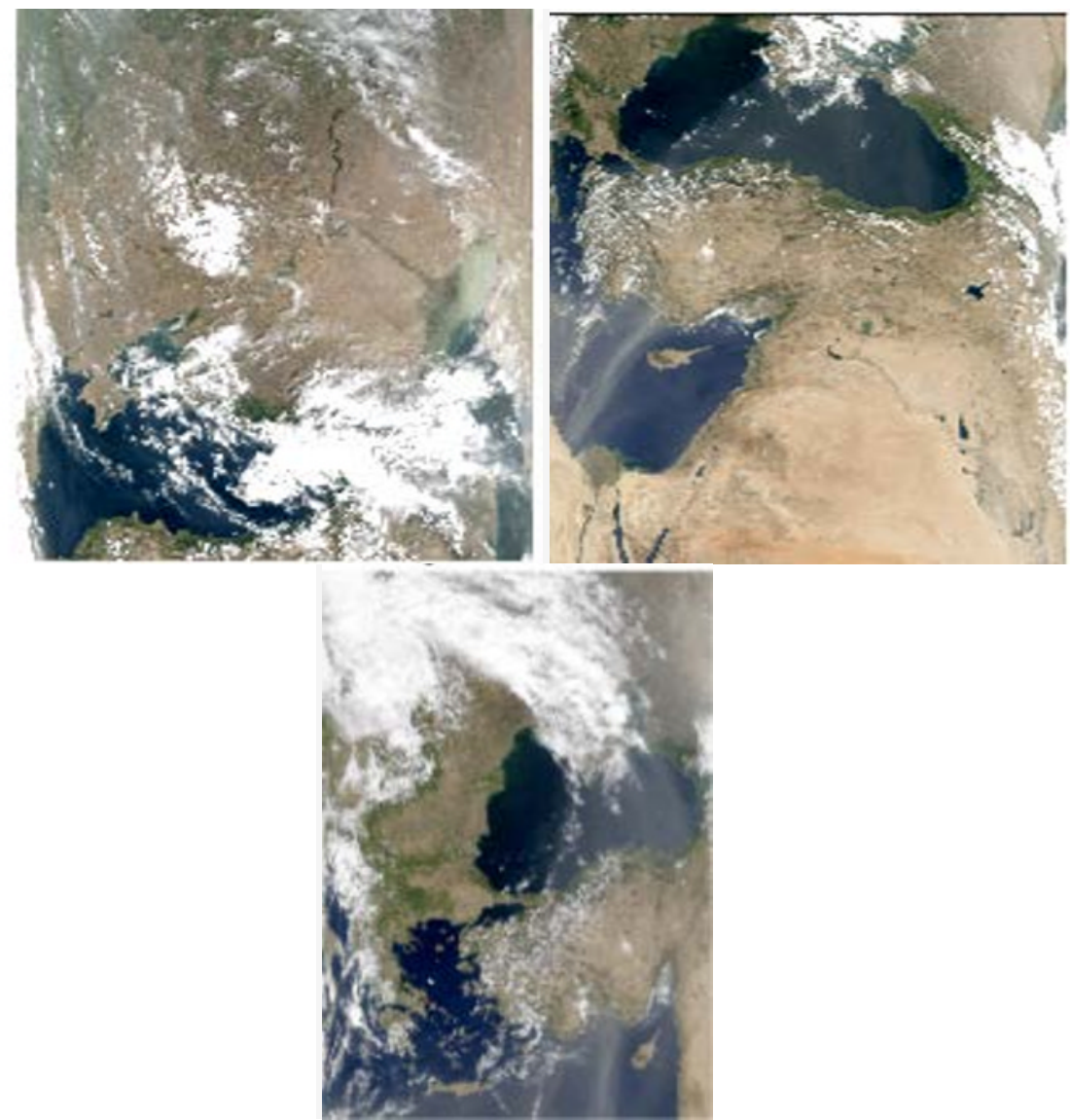

Fig. 3. MODIS (Terra/Aqua) images for 26.09.2020 and 27.09.2020 (peak of dust transfer).

Aerosol subtypes and stratification maps by CALIPSO (The Cloud-Aerosol Lidar and Infrared Pathfinder Satellite Observation) methods were considered as an additional data source to confirm the transfer. Main measuring instrument CALIPSO is three channel radio-meter. For the reason that the system is a lidar, it is noted that CALIPSO is fully polarized in one direction [9]. For the given dates, according to version 3, a massive dust cloud was also detected in the atmosphere over the Black Sea region (Fig. 4).

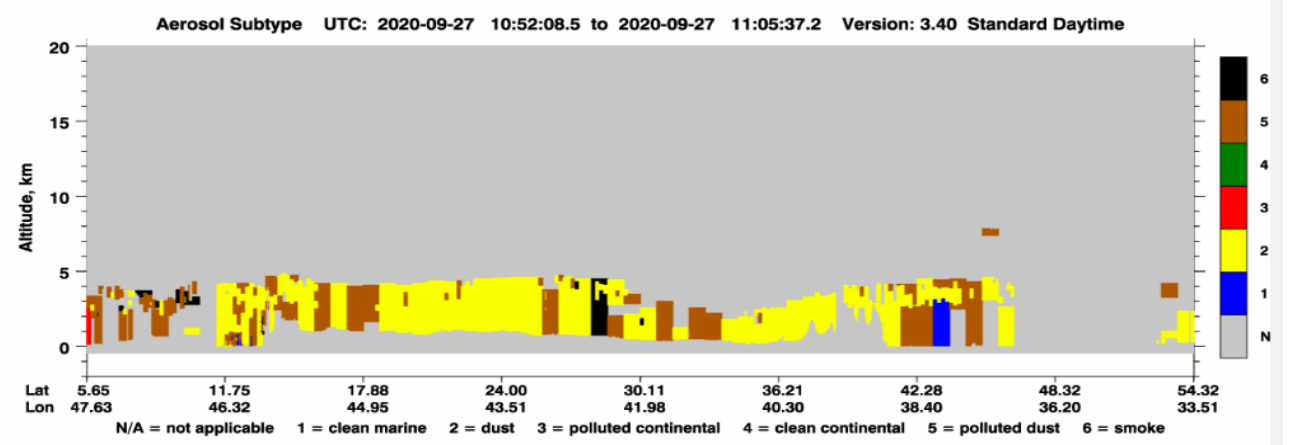

Fig. 4. CALIPSO V3 aerosol stratification map for 27.09.2020 (peak of dust transfer). 
The correlation of the values of aerosol optical thickness ( the main optical characteristic of atmospheric turbidity) with dust transfer events was also investigated. Earlier it was proved that the direct influence of overestimated dust aerosol concentrations overestimated the AOT values [10]. Usually, on the days of dust transport, AOT exceeds the monthly average values by more than 2 to 3 times, depending on the seasonality. Unfortunately, it was not possible to assess the dynamics of the movement of the dust cloud using MODIS satellite data (level 2), since high clouds were observed during the period under study. The dynamics of the dust cloud shows its trajectory from west to east (according to WRF-Dust). To study the variability of the AOT parameter, it was decided to divide the Black Sea zones into three equal parts: western (SW: 41.5; 28.47; NE: 45.86; 32.34), middle (SW: 42.06;32.13 ; NE: 44.24; 36), and eastern(SW: 41.14; 36.3; NE: 44.66; 40.7). For each of the zones, the daily average values of AOT were calculated (Table 1).

Table 1. Changes in the AOT (550 nm) according to the MODIS Terra satellite during the study period in different subregions of the Black Sea (product name :

AOD_550_Dark_Target_Deep_Blue_Combined).

\begin{tabular}{|c|c|c|c|c|c|c|}
\hline Subregion & 24.09 .2020 & 25.09 .2020 & 26.09 .2020 & 28.09 .2020 & 29.09 .2020 & $\begin{array}{c}\text { Monthly } \\
\text { Average }\end{array}$ \\
\hline Western & 0.23 & 0.23 & 0.24 & 0.21 & 0.13 & 0.17 \\
\hline Middle & 0.21 & 0.23 & 0.31 & 0.22 & 0.19 & 0.18 \\
\hline Eastern & 0.18 & 0.22 & 0.28 & 0.32 & 0.33 & 0.19 \\
\hline
\end{tabular}

In addition to the deviation of the aerosol optical thickness, an analysis was made of the change in the remote sensing reflectance (Rrs). It is known that dust is capable of significantly reducing Rrs values due to its absorbing properties [11]. The brightness products provided by MODIS (L2_LAC_OC.nc) on the day before dust transfer (low dust content of the atmosphere - yellow WRF-dust zone) and on the day of main dust transfer (strong dustiness of the atmosphere - red WRF-dust zone) for the matched pixels in middle part of Black Sea were analyzed. Next, the average Rrs values were calculated for different wavelength channels (Table 2).

Table 2. Remote sensing reflectance change according to MODIS Terra data for 26.09.2020 and 27.09.2020.

\begin{tabular}{|l|l|l|l|l|l|l|l|l|l|}
\hline & $\begin{array}{l}\text { AOT_m } \\
\text { ax (865 } \\
\mathrm{nm})\end{array}$ & $\begin{array}{l}\text { Rrs } \\
(412 \mathrm{~nm})\end{array}$ & $\begin{array}{l}\text { Rrs } \\
(443 \mathrm{~nm})\end{array}$ & $\begin{array}{l}\text { Rrs } \\
(469 \mathrm{~nm})\end{array}$ & $\begin{array}{l}\text { Rrs } \\
(488 \mathrm{~nm})\end{array}$ & $\begin{array}{l}\text { Rrs } \\
(531 \mathrm{~nm})\end{array}$ & $\begin{array}{l}\text { Rrs } \\
(547 \mathrm{~nm})\end{array}$ & $\begin{array}{l}\text { Rrs } \\
(555 \mathrm{~nm})\end{array}$ & $\begin{array}{l}\text { Rrs } \\
(678 \\
\mathrm{nm})\end{array}$ \\
\hline 26.09 .20 & 0.12 & 0.0024 & 0.0022 & 0.0028 & 0.0026 & 0.0028 & 0.0016 & 0.0012 & 0.002 \\
\hline 27.09 .20 & 0.32 & -0.0008 & -0.00001 & 0.0013 & 0.0017 & 0.0011 & 0.0009 & 0.0006 & 0.0001 \\
\hline
\end{tabular}

From Table 2, the degree of brightness decrease is clearly noticeable, sometimes by more than 2 times, which is another confirmation of the presence of dust transport predicted by the WRF-dust model. The data have characteristic negative values in the ultraviolet region of the spectrum, which is consistent with the previously obtained results described in [11].

\section{Conclusions}

To make a reliable regional forecast of aerosol dust content in the atmosphere, it is necessary to consider not only the external factors, such as wind energy, soil moisture, but also, it is important to consider the physical characteristics of aerosol particles. Using a comprehensive analysis of the reverse trajectories of aerosol, MODIS and CALIPSO 
satellite data, and analysis of the average daily variability of the AOT and Rrs parameters the predicted dust transport (25.09.2020 - 30.09.2020) of the WRF model was confirmed. Analysis of the AOT variability shown the movement of the dust cloud from the central part of the Black Sea to the East, increasing from values close to the monthly average to the maximum (0.33). The remote sensing reflectance coefficients had characteristic tendencies of changes for the presence of higher concentrations of absorbing aerosol. In the future, it is planned to compare more forecasts with actual data with the corresponding statistical processing of the results.

The study was carried out with the financial support of the Russian Foundation for Basic Research, scientific project No. 19-35-90066, and within the framework of the state assignment programs of the Marine Hydrophysical Institute of the Russian Academy of Sciences on the topic No. 0827-2019-0002.The authors thank the Tom Kucsera, Brent Holben and the Gene Feldman team of National Aeronautics and Space Administration NASA for the calculations of the BTA data. We would also like to express our gratitude to and WRF-Chem group, getting information from WRF-Chem web site.

\section{References}

1. A.S. Papkova, S.O. Papkov, D.M. Shukalo, Sovremennye Problemy Distantsionnogo Zondirovaniya Zemli iz Kosmosa, 17(1), 234-242 (2020)

2. D.V. Kalinskaya, A.V. Varenik, A.S. Papkova, Sovremennye Problemy Distantsionnogo Zondirovaniya Zemli iz Kosmosa, 15(3), 217-225 (2018)

3. X. Kong, R. Forkel, R. Sokhi, P. Suppan, A. Baklanov, M. Gauss, D. Brunner, A. Balzarini, C. Chemel, G. Curci, P. Guerrero, M. Hirtl, L. Honzak, U. Im, L. Juan, Atmospheric Environment, 115, 527-540 (2015)

4. A. Benedetti, J.M. Baldasano, S. Basart, F. Benincasa, O. Boucher, M.E. Brooks, J.-P. Chen, P.R. Colarco, S. Gong, N. Huneeus, L. Jones, S. Lu, L. Menut, J.-J. Morcrette, J. Mulcahy, S. Nickovic, C. Pérez García-Pando, J.S. Reid, T.T. Sekiyama, T.Y. Tanaka, E. Terradellas, D.L. Westphal, X.-Y. Zhang, and C.-H. Zhou, Eds. Springer, 223-265 (2014)

5. U. Rizza, F. Barnaba, M. M. Miglietta, C. Mangia, L. Di Liberto, D. Dionisi, F. Costabile, F. Grasso, G. P. Gobbi, Atmos. Chem. Phys., 17, 93-115 (2017)

6. N.A. Fuks, M. Moskva (1955)

7. J.G. Powers, J.B. Klemp, W.C. Skamarock, C.A. Davis, J. Dudhia, D.O. Gill, M.G. Duda, Bulletin of the American Meteorological Society, 98 (8), 1717-1737 (2017)

8. M.R. Schoeberl and P.A. Newman, J. Geophys, Res., 100, 801-816 (1995)

9. M.-H. Kim, A.H. Omar, J.L. Tackett, M.A. Vaughan, D. M. Winker, C.R. Trepte, Y. Hu, Z. Liu, L.R. Poole, M.C. Pitts, J. Kar, B.E. Magill, Atmos. Meas. Tech. 11, 61076135 (2018)

10. D.V. Kalinskaya, A.S. Papkova, Yu.I. Papkova, K. Gurov, SGEM 2019, 19(4), 10411046 (2019)

11. D. V. Kalinskaya, V. V. Suslin, Fundamental and applied hydrophysics, 8, 59-67 (2015) 